\section{Methodological variables in verbal discrimination learning*}

\author{
FRANK E. FULKERSON and JAMES E. JOHNSON \\ Western Illinois University. Macomb. Ill. 61455
}

In a factorial experiment the study-test method of presenting VD pairs was found 10 be superior to the standard anticipation procedure. Instructions to guess on the first trial resulted in more errors in the anticipation condition but not in the recall condition. as compared to instructions merely to observe the pairs on the first trial. Serial vs zandom ordering of the pairs resulted in no significant differences in performance, but females consistently made fewer errors than males in all conditions

There has been very little research devoted to the effects of variations of methodology on verbal-discrimination (VD) learning. The frequency theory of VD learning proposed by Ekstrand, Wallace. \& Underwood (1966) postulates that intrapair discriminations between "wrong" (W) and "right" (R) items are based on cues provided by differential frequencies of responding to the two items. The primary sources of differential frequency unit accrual are assumed to be representational responses (RRs), pronunciation responses (PRs), and rehearsal of the correct alternative responses (RCRs).

Based on frequency theory alone, one would expect that such methodological variations as anticipation vs recall methods of presentation and serial vs random ordering of presentation would have little, if any, effect on VD learning. Battig \& Switalski (1966), however, found the recall VD procedure to be significantly superior to the standard anticipation VD procedure. This might be explained by the possibility of $\mathrm{Ss}^{*}$ being able to make more RCRs under the recall than under the anticipation procedure. The efficacy of serial vs random ordering of VD pairs, of course, depends upon whether Ss are able to incorporate serial cues into their VD learning strategy.

A methodological variable relatively unique to VD learnirg is whether the $S$ is instructed to guess or merely observe the pairings on the first learning trial. Frequency theory would predict better performance on the part of Ss who merely observe the pairs on the first trial since they are prevented from making any erroneous PRs, at least on an overt basis during this trial.

It was the purpose of the present study to investigate factorially the influence of method of presentation, order of

*This research was supported in part by a grant from the Lniversity Research Council of Western Illinois Lniversity presentation, and initial trial instructions, together with sex of $\mathrm{Ss}$, on VD learning.

\section{DESIGN AND SUBJECTS}

One hundred and twenty-eight Western Illinois University undergraduate volunteers (64 males and 64 females) served as the $S s$ in the experiment. All $S s$ were naive with respect to prior service in experiments employing similar materials and procedures. The design was a 2 by 2 by 2 by 2 factorial, with method of presentation (anticipation or recall), order of presentation (serial or random), initial trial instructions (guessing or observing). and sex of $S$ as the experimental and $S$ variables under investigation. The $S$ s were alternately assigned to the various treatment conditions with the contingency that half of the $\mathrm{Ss}$ in each group be male and the other half female.

\section{WORD LISTS AND PROCEDURES}

The lists were constructed from a pool of 24 minimally associatively related nouns selected from the word-association norms of Palermo \& Jenkins (1964). The 24 nouns were randomly paired to form 12 unrelated pairs. The $W$ and $R$ items of a single pair were printed in juxtaposition and exposed on a screen by a Sears slide projector. For $S s$ in the anticipation condition, each pair first appeared together on a slide: then the pair appeared again on the next slide, this time with the $\mathrm{R}$ item underlined as a means of providing informative feedback. The spatial position of the two items during the second exposure was identical to that of the first exposure on any given trial. Practice in the anticipation condition proceeded at a 2:2-sec rate, with a 6-sec intertrial interval For $\mathrm{Ss}$ in the recall condition, a modified study-test procedure was utilized. First. each of the 12 pairs were presented together for $2 \mathrm{sec}$ on successive slides with no informative feedback: then each of the 12 pairs appeared again for $2 \mathrm{sec}$ each on successive slides with the $\mathrm{R}$ items underlined and with the pairs and $R$ items in identical serial and spatial positions, respectively, to those of the first riewing. A t-sec interval separated the test and study phases of the procedure and a z-see interval. lle study and test phases. Hall of the Sis in both the anticipation and blucking enditions viewed the lists in identical serial order on all trals. The other halt of the Ss rccived three different random orders of presentation to control for serial effects, and the first and third orders served equally often as the starting point for the Ss. Regardless of method or order of presentation, for 6 of the 12 different pairs of items. the $R$ item appeared twice spatially on the right and once on the left in every block of three trials: for the remaining six pairs, the spatial predominance was reversed to control for spatial position effects.

Each $S$ received standard instructions concerning VD learning prior to the start of practice on the list. However. instructions as to performance on the first trial differed. depending on whether the $S$ was to guess or merely observe on the initial trial. Half of the $S$ s in each combination of conditions were instructed to respond on each trial of the learning task, inchuding the first. The other half were instructed merely to observe the pairs on the first trial before beginning to respond on the second trial. Leaming was carried to a criterion of two successive errorless trials

\section{RESULTS AND DISCUSSION}

The statistical analyses and $\bar{X}$ s reported below are based on transformed total error scores (i.e.. $\sqrt{X}+\sqrt{X+1}$ ). which successfully eliminated heterogeneity of variance. The initial guessing-trial data of Ss so instructed were excluded for greater comparability among conditions. A 2 by 2 by 2 by 2 factorial analysis of variance yielded two significant main effects and one significant interaction. First, significantly fewer errois were made by $S$ s under the study-test procedure $(\bar{X}=4.47)$ than by Ss under the standard anticipation condition $(\bar{X}=5.67)$. $F(1,112)=7.16, \quad p<.01$. This finding replicated the previous results of Battig \& Switalski (1966) and indicates that the buildup of frequency units in favor of the right item is more proficient under a recall than under an anticipation procedure. In addition, males made significantly more errors $(\bar{X}=5.80)$ than did females $(\bar{X}=4.31), \quad F(1,112)=11.18, \quad p<.005$. There was also a significant Method by Initial Trial Instruction interaction, $F(1,112)=5.30, p<.025$. This appeared to be the result of $S s$ in the anticipation-guessing condition making significantly more errors $(\bar{X}=6.42)$ than did $S s$ in the other three groups (anticipation-observing $\bar{X}=4.93$, recall-observing $\bar{X}=4.76$, recall-guessing 
$\bar{X}=4.17: p<.05$. Duncan's test). No other main or interaction effects approached significance ( $p s>.25)$.

As a further check to determine whether a guessing effect might be present for both anticipation and recall conditions early in learning. an additional analysis was conducted on the total number of errors for Trials 2 and 3 . (Once again the initial guessing or study trial data was excluded.) The results of the five-way analysis of variance with repeated measures for trials were similar to those for the transformed total errors to criterion. Significantly fewer errors were made by $\mathrm{Ss}$ under the recall procedure (raw score $\bar{X}=3.69$ ) than by $S$ s under the anticipation procedure $(\bar{X}=5.14), F(1,112)=8.47, p<.01$. Males made significantly more errors $(\bar{X}=5.33)$ than did females $(\bar{X}=3.50)$, $F(1,112)=13.40, \quad p<.001$. A practice effect was also evident, as Ss made significantly more errors on Trial 2 $(\bar{X}=2.74)$ than on Trial $3(\bar{X}=1.67)$, $F(1,112)=47.79, p<.001$. Once again there was a highly significant Method by Initial Trial Instruction interaction, $F(1,112)=9.60, p<.005$. The cell means based on total raw error scores for the two $\mathrm{trials}$ combined were 6.25 (ant ic ipation-guessing), 4.03 (anticipation-observing), 4.12 (recall-observing), and 3.25 (recall-guessing). In agreement with the transformed total errors analysis, the anticipation-guessing mean differed significantly from each of the other three means $(p<.001$. Duncan's test), and no other comparisons were significant. In the overall analysis of Trials 2 and 3. no other main or interaction effects approached significance (ps $>.10$ ).

Thus, the instructions to guess on the first trial seem to have had a debilitating effect on performance only under the anticipation procedure. This finding may have resulted from the Ss' initial inability to distinguish between or keep separate PRs and RCRs under the anticipation procedure. The fact that serial ordering did not lead to better learning than random ordering is consistent with findings by Martin \& Saltz (1963) in paired-associate learning. The results of the study indicated. however, that variations in methodology should be taken into account in designing and comparing VD studies, and that when different-sexed $S s$ are used in a VD experiment, they should be assigned equally to all experimental conditions.

\section{REFERENCES}

BATTIG, $W$. F., \& SWITALSKI. R. W Comparison of anticipation and recall procedures in verbal-discrimination learning Psychonomic Science. 1966.6.65-66.
EKSTRAND. B. R. WALLACE. W. P.. \& LNDERWOOD. B. J. A frequency theory of verbal-discrimination learning. Psychological Review, 1966, 6. 566-578.

MARTIN, C. J., \& SALTZ. E. Serial versus random presentation of paired associates.
Journal of Experimental Psychology, 1963 , $65,609-615$.

PALERMO, D. S., \& JENKINS, J. J. Word association norms: Grade school through college. Minneapolis: Lniversity of Minnesota Press, 1964.

\title{
Monetary, affective, and intrinsic incentives in choice reaction time*
}

\author{
GERALD S. BLUM and BARRY M. WOHL $\dagger$ \\ University of California, Santa Barbara, Calif. 93106
}

A female undergraduate, highly trained and practiced in hypnotic techniques, served as the $S$ in a one-choice reaction-time task carried out under three different incentive conditions. Upon viewing her score in milliseconds after each trial, she referred to a chart converting raw scores to an 11-point scale ranging from +5 to -5 . In the monetary condition, each point was worth 5 cents; in the posthypnotically cued affective condition, each point represented a degree of pleasure or anxiety; and in the intrinsic incentive condition, the points had no additional value. Comparisons of the obtained distributions of responses showed no significant differences among the conditions.

In Annett's (1969) words: "Until recently there has been little interest in the role of payoff in reaction time but since instructions involve implicit payoffs some standardization of experimental technique by providing explicit payoffs seems desirable." Johanson (1922) compared punishment and feedback conditions with no feedback; and McCormack, Binding, \& Chylinski (1962) also compared feedback to no feedback. However, there have been no comparisons of different incentives applied to a one-choice reaction-time task with feedback. The availability of a very susceptible highly trained and practiced female undergraduate hypnotic $S$, capable of regulating her feelings of pleasure and anxiety in degree by means of posthypnotic cues. permitted us to compare affective reinforcement (pleasure-anxiety) with two other commonly used incentives, material gain

*This project was supported by NIMH Grant MH 16970-01 (G. S. Blum. Principal Investigator).

We gratefully wish to acknowledge the contributions of the following: Robert Gottsdanker for helpful suggestions and the use of his laboratory facilities: Jed Graef for aid in the statistical analysis: and Stephen Slater for assistance in the data collection. (money) and intrinsic reward of doing well in a task (points). The three incentive conditions were compared for their effect upon S's performance in a one-choice reaction-time task.

\section{METHOD}

The $S$ sat in a soundproof booth in front of a display panel which included the following: a warning light, a Plexiglas rod with two lights built in, a reaction-time score feedback window, a chart adjacent to the window indicating point equivalents for the reaction-time scores (see Table 1), and a card indicating the particular incentive condition ("points," "money," or "cues") for that block of trials. S's task was to hold the Plexiglas rod between the thumb and forefinger of her left hand (nonpreferred) and to move the rod at least $0.3 \mathrm{~mm}$ toward or away from her, depending on whether the half of the rod toward or away from S lit up (Way \& Gottsdanker, 1968). On a given trial the warning light flashed for $50 \mathrm{msec}$. After her response of pushing the rod in one direction or the other, $S$ received visual feedback of her reaction time in milliseconds. S was then given $7 \mathrm{sec}$ to look at the point-equivalents chart (Table 1) in order to translate her reaction-time score into points. 